RESEARCH PAPER

\title{
No association of smoke-free ordinances with profits from bingo and charitable games in Massachusetts
}

\author{
S A Glantz, R Wilson-Loots
}

Tobacco Control 2003;12:411-413

See end of article for authors' affiliations

.....................

Correspondence to: Stanton A Glantz, PhD, Box 1390, University of California, San Francisco, CA 94143-1390, USA; glantz@medicine.ucsf.edu

Received 8 February 2003 Accepted 11 August 2003
Background: Because it is widely played, claims that smoking restrictions will adversely affect bingo games is used as an argument against these policies. We used publicly available data from Massachusetts to assess the impact of $100 \%$ smoke-free ordinances on profits from bingo and other gambling sponsored by charitable organisations between 1985 and 2001.

Methods: We conducted two analyses: (1) a general linear model implementation of a time series analysis with net profits (adjusted to 2001 dollars) as the dependent variable, and community (as a fixed effect), year, lagged net profits, and the length of time the ordinance had been in force as the independent variables; (2) multiple linear regression of total state profits against time, lagged profits, and the percentage of the entire state population in communities that allow charitable gaming but prohibit smoking.

Results: The general linear model analysis of data from individual communities showed that, while adjusted profits fell over time, this effect was not related to the presence of an ordinance. The analysis in terms of the fraction of the population living in communities with ordinances yielded the same result.

Conclusion: Policymakers can implement smoke-free policies without concern that these policies will affect charitable gaming.
S moke-free workplaces substantially and rapidly reduce cigarette consumption, ${ }^{1}$ so the tobacco industry mobilises aggressively against these measures. Because of the industry's low public credibility, however, it does not openly oppose these policies and never raises the issue of the impact on smoking. ${ }^{23}$ Rather, the tobacco industry uses claims of adverse economic impact on other industries, particularly the hospitality industry. ${ }^{4}$ As claims of adverse effects on restaurant and bar revenues, ${ }^{5}$ employment in the hospitality industry, ${ }^{6}$ and tourism ${ }^{7}$ have lost credibility in the face of strong evidence that smoke-free policies have no effect or a positive effect on these businesses, opponents of these policies have used claims of adverse effects on the gaming industry to oppose smoke-free policies. ${ }^{89}$ Because it is widely played, often in smaller communities where efforts to enact local clean indoor air ordinances begin, claims that smoking restrictions will adversely affect bingo games is used as an argument against these public health policies. The fact that bingo is often sponsored by charitable organisations not normally associated with the tobacco industry makes claims of adverse effects on bingo revenues a politically useful claim for the tobacco industry. Bingo is widely played in Massachusetts and the state collects detailed statistics on bingo and related charitable gaming profits, and has seen the passage of many local clean indoor air ordinances. We used these data to assess the impact of $100 \%$ smoke-free ordinances on profits from bingo and other gambling sponsored by charitable organisations in Massachusetts.

\section{METHODS}

In Massachusetts individual communities can vote to allow charitable organisations to sponsor bingo games and other games of chance for fund raising purposes. Non-profit organisations in cities and towns in which voters have voted to allow bingo and other charitable gaming to be conducted. These games are all conducted at the bingo halls. All organisations holding games are licensed by the Massachusetts State Lottery Commission. These organisations report detailed information income and expense statements to the Massachusetts State Lottery Commission every year, which publishes annual statistics on gross receipts, net profit or loss from the games, and other related statistics in each town or city that voted to permit bingo yearly. We obtained these data from the Commission for the years 1985 through 2001. We included all communities that permitted charitable gaming each year; if no games were being played that year, we entered the profit as 0 .

To account for inflation and the state of the underlying economy, we adjusted the profit figures based on Taxes on Commodities Sold (sales and use, meals, alcoholic beverages, motor fuels, and cigarettes) reported by the Commonwealth of Massachusetts Department of Revenue by multiplying the unadjusted charitable gaming profits by the ratio of sales tax revenues in 2001 divided by the sales tax revenues in each year: Adjusted profits in year $y=$ raw profits in year $y$. (sales tax revenues in 2001/sales tax revenues in year y). Gaming statistics are reported by calendar year and tax statistics are reported by fiscal year; we converted tax data to calendar years. This procedure is similar to the procedure of representing restaurant or bar revenues as a fraction of total retail sales. ${ }^{10} 11$

We identified the smoking regulations for each town or city using the American Nonsmokers Rights Foundation (ANRF) local ordinance database and by reviewing copies of the relevant local ordinances. Charitable games were considered included if the ordinance applied to all public places or workplaces unless there was a specific exclusion for these games.

To evaluate the effects of the ordinances on bingo and charitable game profits, we used a general linear model implementation of a time series analysis with net (adjusted) profits as the dependent variable, and community (treated as a fixed effect), year, lagged (by one year) profits, and the length of time the ordinance had been in force as the independent variables. (If the ordinance was in effect for part of the year, we set the ordinance variable to a fraction equal to the number of days that the ordinance was in effect 

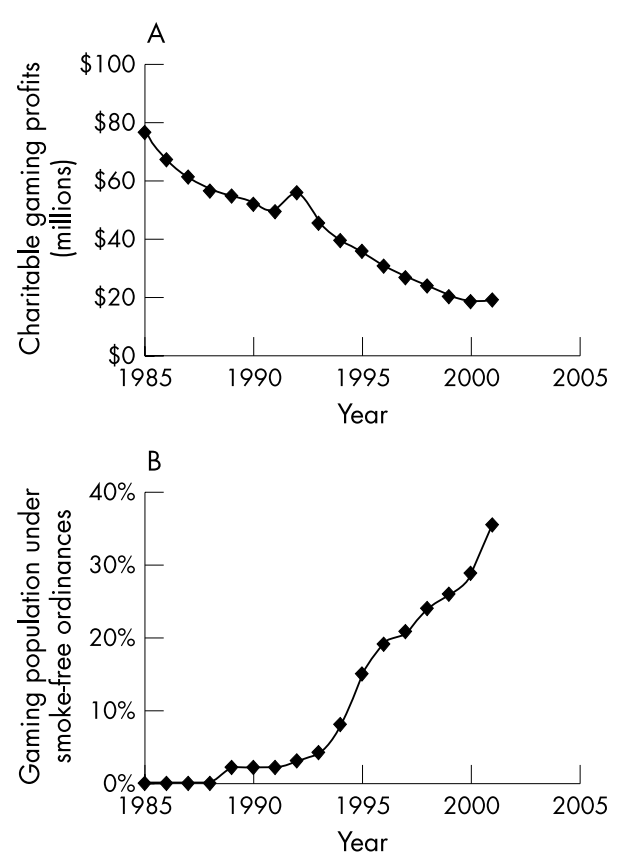

Figure 1 Upper panel: total profits for charitable gaming in Massachusetts, adjusted to 2001 dollars. Lower panel: fraction of people living in communities that permit charitable gaming where the games were required to be smoke-free. Note that the pattern of declining profits in charitable gaming was well established before smoke-free ordinances began being implemented. The fraction of population covered by these ordinances is not a significant predictor $(p=0.303)$ of gaming profits.

divided by 365.) Each data point represented the profits in the community for one year. To account for the wide variation in community size, we conducted an analysis including all communities in a single analysis and also separate analyses for small and larger communities, divided based on the median population of all communities that permitted gaming (14 997). Population figures were obtained from the annual Charitable Gaming Commission reports.

We also conducted a linear regression analysis of total (adjusted) aggregate profits each year as the dependent variable and time and the fraction of the population covered by $100 \%$ smoke-free ordinances that covered bingo and charitable games.

Two hundred and ten communities permitted charitable gaming during one or more years between 1985 and 2001. Seven communities (Easthampton, Holyoke, Montague, Sudbury, Westfield, Westwood, and Winthrop) were excluded because copies of the local ordinances were not available in the ANRF ordinance files.

\section{RESULTS}

Between 1985 and 2001, total adjusted profits from charitable gaming fell over time (fig 1, upper panel), probably because of competition from the Massachusetts Lottery and casinos, which can offer larger prizes. ${ }^{8}$ While this trend has been attributed to smoking restrictions, ${ }^{8}$ this trend predated the enactment of local smoke-free policies (fig l, lower panel). Multiple linear regression of adjusted profits for all games in the state against time, lagged profits, and the percentage of the Massachusetts population in communities that allow charitable gaming but prohibit smoking show a fall in total revenues at a rate of $-\$ 1.71$ (0.95) (SE) million/year $(p<0.096)$, but no effect of the fraction of population covered by smoke-free policies $(-\$ 23.7$ (22.0) million/per cent smoke-free; $\mathrm{p}=0.303$ ).

The analysis of the effect of ordinances in individual communities appears in table 1. Adjusted profits fell over time in all communities considered together, as well as in small (below 14997 population) and larger (above 14998 population) communities which were analysed separately. In all three analyses, revenues fell with time, independently of the effects of the ordinances. The ordinances did not have a significant effect on this trend $(p \geqslant 0.141)$.

\section{DISCUSSION}

Contrary to claims of opponents of local smoke-free policies, which claim substantial negative impacts of smoke-free ordinances on profits from bingo and charitable gaming, these ordinances were not associated with any effect on profits from these games.

One limitation of this analysis is the fact that the large number of data points collected in communities of widely varying sizes led to a wide range of residuals in the general linear model analysis and some departures from normality in the residuals as assessed by normal probability plots. The fact that we included communities that permitted charitable games but had no games biases our results towards underestimating the effects of the smoke-free policies, since many communities who did not have any games did so before any smoke-free policy was implemented.

Given the large number of observations in this analysis (3450), we can be very confident in our conclusion that there is no effect or a positive effect. In particular, we can confidently reject the hypothesis, advanced by opponents of smoke-free policies, that these policies reduce bingo profits. The fact that there were positive effects in larger communities suggests that there may also be positive effects of smoke-free policies on other, larger, gambling establishments. Policymakers can implement smoke-free policies without concern that these policies will adversely affect charitable gaming.

\begin{tabular}{|c|c|c|c|c|}
\hline & \multirow{2}{*}{$\begin{array}{l}\text { Year (change in } \\
\text { revenues per year, } \\
\text { dollars*) }\end{array}$} & \multirow{2}{*}{$\begin{array}{l}\text { Ordinance (change in revenues } \\
\text { per year following ordinance } \\
\text { implementation, dollars*) }\end{array}$} & \multicolumn{2}{|l|}{ n } \\
\hline & & & Communities & Data points \\
\hline All communities & $\begin{array}{l}-798(267) \\
p<0.001\end{array}$ & $\begin{array}{l}+1110 \text { (827) } \\
p=0.179\end{array}$ & 220 & 3247 \\
\hline Small communities & $\begin{array}{l}-648(129) \\
p<0.001\end{array}$ & $\begin{array}{l}+170(468) \\
p=0.716\end{array}$ & 110 & 1634 \\
\hline Larger communities & $\begin{array}{l}-1466(582) \\
p=0.012\end{array}$ & $\begin{array}{l}+2188(1487) \\
p=0.141\end{array}$ & 110 & 1613 \\
\hline
\end{tabular}

Results of general linear model analysis. The model also included a fixed effect for community, and lagged (by one year) adjusted profits.

Communities were divided between large and small based on median population, 14997.

Figures in parentheses indicate standard error of coefficient.

*Dollars are adjusted to 2001 as described in the Methods. 


\section{What this paper adds}

As claims that smoke-free laws adversely affect restaurants and bars have been proven wrong, there have been increasing claims that these laws adversely affect gaming, particularly bingo. This study uses data from Massachusetts to demonstrate that, as with restaurants and bars, smoke-free policies do not affect charitable gaming.

\section{ACKNOWLEDGEMENTS}

We thank Donna Foley of the Massachusetts State Lottery Commission, for providing the data and answering all our questions. This project was supported by National Cancer Institute grant CA61021

\section{Authors' affiliations}

S A Glantz, R Wilson-Loots, Center for Tobacco Control Research and Education, Institute for Health Policy Studies, University of California, San Francisco, San Francisco, California, USA

\section{REFERENCES}

Fichtenberg CM, Glantz SA. Effect of smoke-free workplaces on smoking behaviour: systematic review. BMJ 2002;325:188.

2 Samuels B, Glantz S. The politics of local tobacco control. JAMA 1991;266:2110-17.

3 Traynor M, M B, Glantz S. New tobacco industry strategy to prevent local tobacco control. JAMA 1993;270:479-86.

4 Scollo M, Lai A, Hyland A, et al. A review of the quality of studies on the economic effects of smoke-free policies on the hospitality industry. Tobacco Control 2003:12:13-20.

5 Glantz S. Smokefree restaurant ordinances don't affect restaurant business period. Journal of Public Health Management \& Practice 1999;5(1):vi-ix.

6 Hyland A, Cummings K. Restaurant employment before and after the New York City Smoke-free Air Act. Journal of Public Health Management \& Practice 1998;5(1):22-27.

7 Glantz SA, Charlesworth A. Tourism and hotel revenues before and after passage of smoke-free restaurant ordinances. JAMA 1999;281:1911-8.

8 Associated Press. Bingo's number may be up. New Bedford Standard Times 1996 December 2.

9 Haynes K, Kerkstra P. Ban may spell trouble; Smoking: bingo parlors say business has dropped because of new state law; charities that benefit from the games fear long-term impact. Los Angeles Times 1998 February 2:Sect. B1.

10 Glantz S, Smith LRA. The effect of ordinances requiring smoke-free restaurants on restaurant sales. Am J Public Health 1994;84:1081-5.

11 Glantz S, Smith L. Erratum for "The effect of ordinances requiring smoke-free restaurants on restaurant sales". Am J Public Health 1997:87:1729-30.

\section{The lighter side}

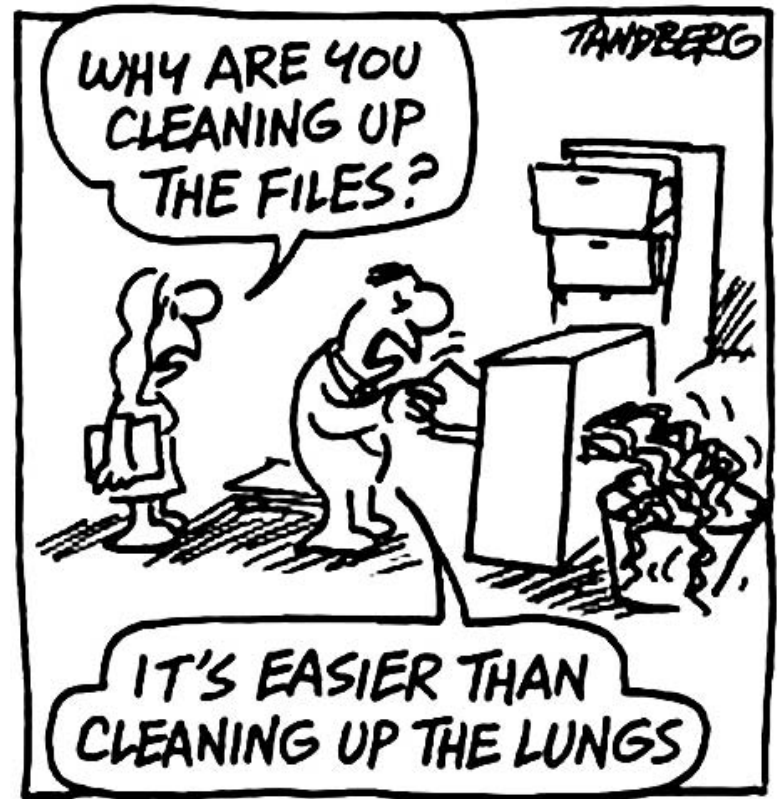

๑Tandberg, The (Melbourne) Age, 2003. 